"Center for Pulmonary Hypertension, Thoracic Clinic, University of Heidelberg, Heidelberg, Germany.

Correspondence: R. Naeije, Dept of Pathophysiology, Erasmus Campus, CP 604, Route de Lennik, 808, B-1070 Brussels, Belgium. E-mail: rnaeije@ulb.ac.be

Support Statement: This study was funded by a grant from the European Union Fifth Framework programme "Disposition to PPH, QLGI-CT-2002-01116".

Statement of Interest: Statements of interest for J-L. Vachiéry, E. Grunig and R. Naeije can be found at www.erj.ersjournals. $\mathrm{com} / \mathrm{site} / \mathrm{misc} /$ statements.xhtml

\section{REFERENCES}

1 Task Force for Diagnosis and Treatment of Pulmonary Hypertension of European Society of Cardiology (ESC), European Respiratory Society (ERS), International Society of Heart and Lung Transplantation (ISHLT), et al. Guidelines for the diagnosis and treatment of pulmonary hypertension. Eur Respir J 2009; 34 1219-1263.

2 Newman JH, Phillips JA, Lloyd JE. Narrative review: the enigma of pulmonary arterial hypertension: new insights from genetic studies. Ann Intern Med 2008; 148: 278-283.

3 Grunig E, Weissmann S, Ehlken N, et al. Stress Doppler echocardiography in relatives of patients with idiopathic and familial pulmonary arterial hypertension: results of a multicentric European analysis of pulmonary artery pressure response to exercise and hypoxia. Circulation 2009; 119: 1747-1757.
4 Yock PG, Popp RL. Noninvasive estimation of right ventricular systolic pressure by Doppler ultrasound in patients with tricuspid regurgitation. Circulation 1984; 70: 657-662.

5 Kitabatake A, Inoue M, Asao M, et al. Noninvasive evaluation of pulmonary hypertension by a pulsed Doppler technique. Circulation 1983; 68: 302-309.

6 Abbas AE, Fortuin FD, Schiller NB, et al. A simple method for noninvasive estimation of pulmonary vascular resistance. $J$ Am Coll Cardiol 2003; 41: 1021-1027.

7 Chemla D, Castelain V, Humbert M, et al. New formula for predicting mean pulmonary artery pressure using systolic pulmonary artery pressure. Chest 2004; 126: 1313-1317.

8 Christie J, Sheldahl LM, Tristani FE, et al. Determination of stroke volume and cardiac output during exercise: comparison of twodimensional and Doppler echocardiography, Fick oximetry, and thermodilution. Circulation 1987; 76: 539-547.

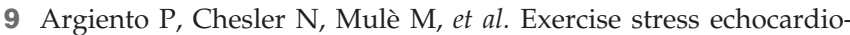
graphy for the study of the pulmonary circulation. Eur Respir J 2010; 35: 1273-1278.

10 Reeves JT, Linehan JH, Stenmark KR. Distensibility of the normal human lung circulation during exercise. Am J Physiol Lung Cell Mol Physiol 2005; 288: L419-L425.

11 Frank DB, Lowery J, Anderson L, et al. Increased susceptibility to hypoxic pulmonary hypertension in Bmpr2 mutant mice is associated with endothelial dysfunction in the pulmonary vasculature. Am J Physiol Lung Cell Mol Physiol 2008; 294: L98-L109.

12 Stickland MK, Welsh RC, Petersen SR, et al. Does fitness level modulate the cardiovascular hemodynamic response to exercise? J Appl Physiol 2006; 100: 1895-1901.

13 Groepenhoff $\mathrm{H}$, Overbeek MJ, Mulè M, et al. Exercise pathophysiology in patients with chronic mountain sickness. Chest 2012; [Epub ahead of print DOI: 10.1378/chest.11-2845].

DO|: $10.1183 / 09031936.00021712$

\title{
Diabetes is a risk factor for tuberculosis in the Inuit population of Greenland
}

\section{To the Editors:}

Diabetes is a known risk factor for tuberculosis (TB), and studies across populations and geographic regions suggest substantial increased risks of developing TB ranging from 1.16 to 7.83 with co-existing diabetes [1]. It is suggested that the risk is due to latent $\mathrm{TB}$ infections being activated by the hyperglycemia associated with diabetes. The evolving epidemiology of concurrent diabetes and TB in settings where both diseases are frequent is therefore looked upon with special concern. The prevalence of diabetes among the Greenland Inuit is high (10\%) and increasing [2]. Meanwhile, the TB incidence remains high with an estimated 180 cases per 100,000 suggesting ongoing TB transmission [3]. The aim of this study was to quantify the effect of diabetes on TB development among the Greenland Inuit.

We conducted a retrospective cohort study. Study participants comprised ethnic Inuit who participated in two previously conducted cross-sectional studies where diabetes status were assessed; Inuit Health in Transition Study (IHIT) [4] and the Greenland Population Study (B99) [2]. All study participants in
IHIT and B99 were randomly selected from the Civil Registration System (CRS) in order to represent the entire Greenlandic population. The CRS provides all citizens of Greenland with a unique identification number at birth, facilitating tracing of persons through all public registries. The CRS identifier enabled follow-up of study participants in the National TB register. The study was approved by the Ethics Review of Greenland.

Participants not previously diagnosed with diabetes (98\%) underwent a standard oral glucose tolerance test (OGTT). Participants were categorised with diabetes if previously diagnosed with diabetes or if fasting and 2-h blood glucose levels were $\geqslant 7 \mathrm{mmol} \cdot \mathrm{L}^{-1}$ and $\geqslant 11.1 \mathrm{mmol} \cdot \mathrm{L}^{-1}$, respectively. Weight and height were measured and body mass index (BMI) calculated. Age and sex of participants were determined from CRS data. Place of residence, divided into town or settlement, was likewise derived from the CRS registry.

TB is a mandatory notifiable disease in Greenland and all incident cases diagnosed by a medical doctor are recorded in the National TB register [5]. For the present study, all incident 


\begin{tabular}{|c|c|c|}
\hline \multirow[t]{2}{*}{ TABLE 1} & \multicolumn{2}{|c|}{$\begin{array}{l}\text { Incidence rate ratio (RR) of tuberculosis with } \\
\text { co-existing diabetes }\end{array}$} \\
\hline & $\mathbf{R R}$ & $95 \% \mathrm{Cl}$ \\
\hline \multicolumn{3}{|l|}{ Crude } \\
\hline Diabetes & 2.66 & $0.41-10.3$ \\
\hline Non-diabetes & 1 & \\
\hline \multicolumn{3}{|l|}{ Adjusted $^{\#}$} \\
\hline Diabetes & $11.7^{*}$ & $1.48-65.9$ \\
\hline $\mathrm{BMI} \mathrm{kg} \cdot \mathrm{m}^{-2}$ & $0.67^{*}$ & $0.51-0.84$ \\
\hline Age yrs & $0.93^{*}$ & $0.88-0.97$ \\
\hline \multicolumn{3}{|l|}{ Sex } \\
\hline Males & 1 & \\
\hline Females & $0.16^{*}$ & $0.02-0.63$ \\
\hline \multicolumn{3}{|c|}{ Place of residence } \\
\hline Town & 1 & \\
\hline Settlement & 1.82 & $0.47-6.11$ \\
\hline
\end{tabular}

TB cases recorded among the study participants were retrieved from the National TB register; however, only TB cases recorded after diabetes assessment were included in the study.

Diabetes status, age, sex, place of residence and BMI retrieved from B99 and IHIT were linked to the National TB register and the death register by the CRS number. Participants were followed from entry into either B99 or IHIT until TB diagnosis, death/emigration or December 31 2010, whichever came first. The incidence rate ratios (RRs) for developing TB according to diabetes status were estimated by log-linear Poisson regression, using the logarithm of person years as offset. The RRs were adjusted for BMI, age, sex and place of residence in a multivariate regression analyses. To evaluate the robustness of our results, we also estimated the crude estimate using exact Poisson regression with mid-p confidence intervals (CIs). This only led to a minor widening of the confidence interval. Level of significance was set at 5\%. All analyses were performed in SAS version 9.2 (SAS Institute, Cary, NC, USA).

A total of 3,012 study participants were identified as Inuit and registered in CRS, of these 276 were excluded from further analysis for not meeting the inclusion criteria (prior TB $(n=257)$ and missing sample dates $(n=19)) .2,736$ were included in the analyses. Mean follow-up was 4.97 yrs. Approximately $44 \%$ were males (49\% in Greenland as a whole), and the median age was 45 yrs (interquartile range: $37-56$ yrs) (40 yrs in Greenland (interquartile range: $30-50 \mathrm{yrs}$ )). Median BMI was $25.6 \mathrm{~kg} \cdot \mathrm{m}^{-2}$ (interquartile range: $22.5-29.5 \mathrm{~kg} \cdot \mathrm{m}^{-2}$ ) and $74 \%$ lived in towns.

A total of 281 (10.3\%) participants had diabetes and $11(0.4 \%)$ were registered with TB during follow-up. The unadjusted TB incidence rate was 2.66 times higher in participants with diabetes compared with participants without diabetes (table 1). Adjusting for age, sex, BMI and place of residence, however, entailed a significantly increased RR of $11.7(\mathrm{p}<0.01)$. High BMI and female sex had a protective effect on the risk of developing TB.
The present study is, to our knowledge, the first study to explore and quantify the effect of diabetes on the risk of developing TB in an Inuit population. The present study found the TB incidence rate to be 11.7 times higher among Inuit with diabetes relative to Inuit without when adjusting for age, sex, place of residence and BMI. The results of the present study are overall in accordance with similar studies assessing the link between diabetes and TB. However, the magnitude of the RR in this study is higher than the risk identified in most studies. Thus, a prospective study from Mexico found a seven-fold increase in TB rates among persons with diabetes relative to persons without diabetes [6]. The link between diabetes and TB was also explored in indigenous populations; thus Mori et al. [7], found diabetes to be more frequent in Oglala Sioux Indians diagnosed with TB compared with Indians without TB (odds ratio 5.2).

Surprisingly, a study of TB risk factors recently conducted in Greenland, could not identify diabetes as a risk factor for TB [8]. However, diabetes was self-reported in the study and therefore subject to major under-reporting as an estimated $70 \%$ of people with diabetes in Greenland are unaware of their diabetes [2]. Additionally, the study population comprised mixed Inuit/ Danish ethnicity. A study from Denmark found an odds ratio of 1.18 (95\% CI 0.96-1.45) of active TB with a prior diagnosis of diabetes [9]; the discrepancy to our study is most likely due to the low risk of latent TB in Denmark compared with Greenland [10].

Adjusting for age, sex, BMI and place of residence entailed a dramatic increase in the RR due to the strong association between BMI and TB, and between sex and TB. The apparent strengthening of risk estimates after confounder adjustment has been found in similar studies $[1,7]$. The seemingly protective effect of a higher BMI is in accordance with studies suggesting underweight to be a substantial risk factor for active TB [8]. Nonetheless, it is also plausible that persons with advanced TB symptoms (e.g. extensive weight loss) are more likely to seek medical attention and, therefore, more often registered with TB. However, a low BMI may also be an expression of more advanced diabetes and hence, longer duration of unknown diabetes. It is well known that the TB incidence is lower among females, which is also in accordance with the finding in this study [8]. Likewise, participants living in towns had lower RR of developing TB than participants living in settlements, consistent with one study, where living in settlements was a risk factor for TB [8].

A major strength of the present study is the longitudinal study design allowing the calculation of RR and thus assessing the temporal order of the association of diabetes and TB. Furthermore, as diabetes is unknown in an estimated $70 \%$ of diabetes cases in Greenland [2], the assessment of diabetes from OGTT is a substantial strength. Likewise, TB cases are diagnosed by a medical professional and microbiologically confirmed before registration in the National TB register.

Furthermore, as assessment of diabetes is made at point of study entry in IHIT and B99, the duration of diabetes exposure, is not taken into account. Hence, unknown diabetes may have facilitated the occurrence of TB before a confirmed diabetes diagnosis, underestimating the effect of diabetes on the risk of TB development. Additionally, it is possible that unmeasured confounders, not adjusted for in the present study may account for some of the effect of diabetes on the risk of developing TB. 
The contribution of diabetes is still widely overlooked in TB prevention efforts [1]. In this sample of Greenland Inuit where both HIV and undernutrition remain uncommon, the risk of developing TB was markedly higher in persons with co-existing diabetes than in persons without. The very high risk associated with diabetes suggests potential reduction in the Greenland TB incidence rates through incorporating diabetes control and prevention in TB prevention schemes. However, the validity of the results should be confirmed in a larger sample size, preferentially by applying longer follow-up time to the study cohort.

\section{Stine Byberg*, Bolette Soborg", Mikael Andersson ", Peter Bjerregaard ${ }^{+}$and Marit E. Jørgensen*}

*Epidemiology group, Steno Diabetes Center A/S, Gentofte, \#Department of Infectious Disease Epidemiology, Statens Serum Institut, "Department of Epidemiology Research, Statens Serum Institut, and ${ }^{+}$Centre of Health Research in Greenland, National Institute of Public Health, University of Southern Denmark, Copenhagen Denmark.

Correspondence: S. Byberg, Epidemiology Group, Steno Diabetes Center A/S, Niels Steensensvej 2-4, DK-2820, Gentofte, Denmark. E-mail: stinebyberg@gmail.com

Statement of Interest: None declared.

Acknowledgements: The present study received funding from the Commission of Scientific Research in Greenland (Nuuk, Greenland). The B99 and IHIT studies were funded by the Danish Medical Research Council and Karen Elise Jensen's Foundation.

\section{REFERENCES}

1 Jeon CY, Murray MB. Diabetes mellitus increases the risk of active tuberculosis: a systematic review of 13 observational studies. PLoS Med 2008; 5: e152.

2 Jørgensen ME, Bjerregaard P, Borch-Johnsen K. Diabetes and impaired glucose tolerance among the inuit population of Greenland. Diabetes Care 2002; 25: 1766-1771.

3 Soborg B, Koch A, Thomsen VØ, et al. Ongoing tuberculosis transmission to children in Greenland. Eur Resp J 2010; 36: 878-884.

4 Bjerregaard P. Greenland survey 2005-2010. Population sample and survey methods. 2nd Edn. www.si-folkesundhed.dk/upload/ inuit_health_in_transition_greenland_methods_5_2nd_revision.pdf Date last updated: 2011. Date last accessed: September 12, 2011.

5 Søborg C, Søborg B, Puoelsen S, et al. Doubling of the tuberculosis incidence in Greenland over an 8-years period (1990-1997). Int J Tuberc Lung Dis 2001; 5: 257-265.

6 Ponce-De-Leon A, Garcia-Garcia MAL, Garcia-Sancho MAC. Tuberculosis and diabetes in Southern Mexico. Diabetes Care 2004; 27: 1584-1590.

7 Mori MA, Leonardson G, Welty TK. The benefits of isoniazid chemoprophylaxis and risk factors for tuberculosis among Oglala Sioux Indians. Arch Intern Med 1992; 152: 550.

8 Ladefoged K, Rendal T, Skifte T, et al. Risk factors for tuberculosis in Greenland: case-control study. Int J Tuberc Lung Dis 2011; 15: 44-49.

9 Leegaard A, Riis A, Kornum JB, et al. Diabetes, glycemic control, and risk of tuberculosis. Diabetes Care 2011; 34: 2530-2535.

10 Søborg B, Andersen AB, Larsen $\mathrm{HK}$, et al. Detecting a low prevalence of latent tuberculosis among health care workers in Denmark detected by $M$. tuberculosis specific IFN- $\gamma$ whole-blood test. Scand J Infect Dis 2007; 39: 554-559.

\section{Outcomes of a tuberculosis contact investigation programme in Italy}

\section{To the Editors:}

Mycobacterium tuberculosis transmission is affected by several key factors, such as contagiousness of the index tuberculosis (TB) case, immune status and susceptibility of the exposed TB contact, duration and patterns of contact between the index TB case and the exposed TB contact, and characteristics of the environment within which such contact occurs [1-3]. Tracing strategies that allow the early identification and appropriate treatment of TB contacts with latent $\mathrm{TB}$ infection (LTBI) or active TB should be a priority of TB control programmes with adequate resources $[3,4]$.

In agreement with the guidelines laid out by the Italian Ministry of Health, the Piedmont Region has activated and regularly updated TB contact investigation procedures [5]. We used data from the Piedmont Region TB contact investigation programme to assess the role of selected risk factors for TB infection (TBI) among TB contacts in the city of Turin, Italy. For each suspected or confirmed pulmonary TB case, active contact investigation was conducted among household members, close contacts and regular contacts, defined according to the stone-in-the-pond method [6] Passive investigation was used for occasional contacts [5].

The Piedmont TB notification systems were used to identify pulmonary TB cases between January 2002 and December 2008. TB cases were classified into three categories of contagiousness: 1) sputum smear-positive and culture-positive (acid-fast bacillus positive $(\mathrm{AFB}+))$; 2 ) sputum smear-negative but culturepositive (CULT+); and 3) sputum smear-negative and culturenegative or not examined, i.e. other than defined (OtD). Interviews were conducted with each $\mathrm{TB}$ case to identify $\mathrm{TB}$ contacts, defined as anyone having shared air with an active TB case. All traced TB contacts were screened for active TB or LTBI using the tuberculin skin test (TST). The TST was performed using tuberculin purified protein derivative (5 IU) according to the Mantoux method [3]. TB contacts were classified as infected either if the induration was $\geqslant 5 \mathrm{~mm}$ in diameter regardless of any prior bacille Calmette-Guérin (BCG) vaccination [3] or if clinical, bacteriological or radiological signs or symptoms of manifest disease were present. If the TST was negative, a second 